\title{
The Video Conferencing Learning Environment in Distance Education: A Study of the Interaction Pattern
}

\author{
Omar Majid, Zuraidah A Rahman, Noraida A Ghani, \\ Saw Kim Guan, Rozhan M Idrus \& Hanafi Atan \\ School of Distance Education \\ Universiti Sains Malaysia \\ 11800 Pulau Pinang \\ Malaysia \\ omar@usm.my, arzurai@usm.my, noraida@usm.my, \\ kgsaw@usm.my, rozhan@usm.my \& ahanafi@usm.my
}

\begin{abstract}
This article reports on the study undertaken to elucidate the pattern of interactions in the Video Conferencing Learning Environment (VCLE) used as a course delivery mechanism in distance learning. The study involved transcribing the recorded course delivery sessions conducted in the VCLE for three undergraduate Physics courses. The model of interaction used in this study was based on the Oliver \& McLoughlin [5] interaction model consisting of five interactive dimensions, namely, the social, procedural, expository, explanatory and cognitive dimensions across five combinations of dialogue exchanges between teachers, students and the class as a whole. The results revealed that there were high frequencies of two-way exchanges between teachers and students in the expository, explanatory and cognitive interactive dimensions. The implication of these findings in terms of the quality of knowledge construction and high level student understanding of the course contents will be discussed and elaborated.
\end{abstract}

\section{Introduction}

The advancement of communication technologies has provided many opportunities in the delivery of course materials for open and distance education learning (ODL). One such learning environment created and used extensively in ODL is the Video Conferencing Learning Environment (VCLE). The VCLE may be defined as an environment that deploys telecommunications to achieve real-time interactions; it involves the transmission of image (video) and speech (audio) back and forth between physically separated locations [1]. In this learning environment, two or more persons are located in different locations but they can see and hear each other at the same time and thus they are able to share the learning environment with communication and collaboration. This environment has the capability to combine diverse endpoints into a single setting, where audio and/or video clips, graphics, animations and computer applications from each end can be shared in real time, thus enabling whole new levels of interactions and generating entirely new communication and ideas among teachers and students [2].

The use of the VCLE in ODL appears to render more advantages than other conventional delivery methods mainly due to the forms of communication which it supports. Within the VCLE, teachers and leamers have a heightened capacity to communicate and interact. The importance of interactions in successful teaching episodes is attested by considerable research [3][4][5]. Laurillard [6] argued that learning comprises a number of interactive processes without which concepts, skills and knowledge tend to be inert and lacking in the generalizability needed for transfer and application to other domains. McLouglin \& Oliver [5] asserted that resulting interactions are able to engage learners and cause them to reflect on and articulate ideas; they encourage and facilitate cognition, promoting the learners' intellectual operations and thinking process.

Many conceptual frameworks have been put forward to describe the pattern and structure of interactions in the technology-assisted course delivery in distance education [7][8][9][10][11]. Moore [7] proposed the lecturer-student interaction, the learner-learner interaction and the learner-content interaction as the three main types of interactions that can be supported by synchronous interactive technology. Fulford \& Zhang [8] identified personal interaction, overall 
interaction and satisfaction as critical factors to measure successes in distance education. Robson [9], on the other hand, used interpretative methodology and classified interactions in terms of patterns of exchanges between the lecturer and students. Fahy [11] classified interactions in terms of the functionality of the exchanges such as referential or engaging interactions, reflections, acknowledgements, apologies, etc.

In this study, the interaction model proposed by Oliver \& McLouglin [5], which has also been similarly used in the study of interactions in the e-learning portal Learning Management System (LMS) by Foong et al. [12] and Syed et al. [13], is utilised as a framework. It is a content analysis model which consists of five critical dimensions that provide multilevel understanding of the learning process. The critical dimensions and their corresponding descriptions are depicted in Table 1.

Table 1. Dimensions of interactions (Oliver \& McLoughlin [5])

\begin{tabular}{|l|l|}
\hline $\begin{array}{l}\text { Dimensions } \\
\text { of } \\
\text { interactions }\end{array}$ & Descriptions \\
\hline Social & $\begin{array}{l}\text { Lecturer-student talk, establishing } \\
\text { and developing rapport }\end{array}$ \\
\hline Procedural & $\begin{array}{l}\text { Lecturer-student dialogue } \\
\text { involving information exchange on } \\
\text { course requirements and } \\
\text { procedures }\end{array}$ \\
\hline Expository & $\begin{array}{l}\text { Student or lecturer demonstrating } \\
\text { knowledge or skill in response to a } \\
\text { direct request from one another }\end{array}$ \\
\hline Explanatory & $\begin{array}{l}\text { Lecturer using student responses to } \\
\text { explain knowledge and develop } \\
\text { course content }\end{array}$ \\
\hline Cognitive & $\begin{array}{l}\text { Lecturer providing constructive } \\
\text { feedback to student to reflect and } \\
\text { to reconsider an alternative } \\
\text { perspective/reality }\end{array}$ \\
\hline
\end{tabular}

In the dialogue exchanges, there were basically two parties involved in the interaction, namely, the initiator and the respondent. These could each be a lecturer, student or class. Accordingly, the types of interactions were further classified into categories as depicted in Table 2.

The purpose of this study was to investigate the ways lecturers used the interactive capabilities of the VCLE in the course delivery mechanism in distance learning, utilising the framework as proposed by Oliver \&
McLoughlin [5]. Specifically, this study looked at the types of interactions deployed by lecturers in their teaching and the extent to which these interactions were utilised in order to establish patterns of use and to quantify the lecturers' preferred form of interaction. In undertaking this study, the following research questions were put forward:

a. What were the forms of interactions supported by the VCLE in the delivery of courses in distance education?

b. To what extent were these forms of interactions being deployed by the lecturer?

c. Did the interactions deployed contribute to the enhancement of the quality of instruction in the VCLE?

Table 2. Categories of exchanges

\begin{tabular}{|l|l|}
\hline $\begin{array}{l}\text { Categories of } \\
\text { exchanges }\end{array}$ & Descriptions \\
\hline L-C & $\begin{array}{l}\text { Lecturer initiated and directed the } \\
\text { whole class }\end{array}$ \\
\hline L-S & $\begin{array}{l}\text { Lecturer initiated and directed } \\
\text { specific students }\end{array}$ \\
\hline S-L & $\begin{array}{l}\text { Students initiated and directed the } \\
\text { lecturer }\end{array}$ \\
\hline S-S & $\begin{array}{l}\text { Students initiated and directed } \\
\text { other students }\end{array}$ \\
\hline S-C & $\begin{array}{l}\text { Students initiated and directed the } \\
\text { whole class }\end{array}$ \\
\hline
\end{tabular}

\section{Methodology}

At the School of Distance Education (SDE), Universiti Sains Malaysia (USM), the VCLE has been utilised since 1996 as a delivery mechanism for teaching and learning for distance learners. The system connects the USM main campus studio to ten other video conferencing sites at the regional centres throughout Peninsular Malaysia. At all the video conferencing sites, two video monitors are used - one monitor to display either the image of the lecturer (the video display mode) or the graphics-power point slides or materials hand written by him (the graphics display mode). These two modes of display are controllable by the teachers at the USM main video conferencing site, using the front control panel. The other monitor is the voice-triggered video monitor that displays the images of students at a particular regional centre.

The courses identified in this study were Physics undergraduate courses offered by the SDE in the 2004/2005 academic session. These courses were utilised in this study as Physics is one of the four 
science majors offered by the School. Due to the nature of Physics that requires inquiry into physical phenomena and the resolution of real world problems, a high degree of interactions taking place was anticipated during the delivery of the courses. A total of three courses was selected in this study and each of the courses lasted for an hour; the three courses were conducted by three different senior teachers of the SDE.

The analysis of the interaction pattern involved transcribing the recorded sessions into appropriate classifications of interactions, namely the social, procedural, expository, explanatory and cognitive interactions. The classification was done by considering the questions, statements and all the ensuing replies that took place between the lecturer and students and between the students themselves. On most occasions, the interactions involved multiple exchanges. For the purpose of this study, a single interaction was said to have occurred when an individual stopped conveying a message. A new interaction was then considered to have commenced when the communication moved to another individual or the communication from the same individual shifted to a completely new topic or to a new instructional intent.

\section{Results and Discussion}

The results of the analysis are depicted in Table 3-5. The analysis revealed that interactive technologies played a critical role in course delivery. There were, however, a number of behaviourial patterns evident across all the three classes which provided some interesting insights into how collaboration took place.

Table 3. Numbers and types of interactions in Lesson $A$

\begin{tabular}{|l|l|l|l|l|l|l|l|l|l|l|}
\hline $\begin{array}{l}\text { Types of } \\
\text { interactions }\end{array}$ & \multicolumn{3}{|l|}{ Video displays } & \multicolumn{3}{l|}{ Graphic displays } \\
\hline & T-C & T-S & S-T & S-C & S-S & T-C & T-S & S-T & S-C & S-S \\
\hline Social & 3 & 1 & 1 & & 1 & & & & & \\
\hline Procedural & 4 & 11 & 12 & & & & & & & \\
\hline Expository & & & & & & 2 & & 1 & & \\
\hline Explanatory & & & & & & 9 & 7 & 10 & & \\
\hline Cognitive & & & & & & 1 & 3 & 3 & & \\
\hline
\end{tabular}

In Lesson $A$, it was evident that the teacher took advantage of the interactive capabilities of the technology in both the video display and the graphics display modes. However, a distinctive pattern emerged that differentiated the types of interactions occurring in these two modes. In the video display mode, where students were able to see the image of the lecturer in person, the interaction type was predominantly social and procedural. The social interaction involved information exchanges that attempted to establish rapport, roll calling, the status of student readiness, checking for the audio level and video quality as well as the students' sitting arrangements. On the hand, the procedural interaction related to general questions about the course such as assignment deadlines, learning materials as well as background knowledge and learning strategies.

In the graphics display, the interaction was mostly explanatory whereby the teacher provided feedback on students' responses in order to transmit knowledge and develop students' understanding of the course content.
There was a fairly significant number of teacher-class (T-C), teacher-student (T-S) and student-teacher (S-T) interactions involving the cognitive type. In these interactions, the teacher provided a constructive feedback to a student response causing the student to reflect and to reconsider an alternative perspective and reality of the concept being discussed.

The flow of interactions is a combination of one-to-one and one-to-many, i.e., the teacher to the student, the student to the teacher as well the teacher to the class. There was almost no interaction involving students among themselves or between the student and the class. Since there was a fairly high number of T-C, T$\mathrm{S}$ and S-T recorded, it was evident that the students were involved in a high degree of collaborative activities with the teacher directing the questions to individual students and the students responding to the questions posed to them.

Table 4 depicts the breakdown of interactions during the transmission of Lesson B. As opposed to Lesson $A$, the substantial number of interactions occurring in 
the video display mode was mostly of the explanatory and cognitive types with two-way exchanges between the teacher and students and vice versa as evident by the high frequency of T-S and S-T recorded.

When the graphics display setting was used, there were even higher degrees of collaborations and interactions occurring in the class as the T-S and S-T recorded substantially higher frequencies. It is also interesting to note that these interactions were in the domain of the expository, explanatory and cognitive types. This indicated that the lecturer had successfully engaged the students in a dialogue and communication that brought about reflection on the content and the process of learning that stimulated deeper levels of understanding of the course content. The expository type recorded a high frequency and, to a lesser extent, the explanatory type. The expository type can be regarded as narrative whereas the explanatory interactions can be regarded as negotiative (Laurillard [8]). The high T-S frequency recorded in the cognitive dimension indicated that the teacher had successfully promoted the desired and preferred types of interactions and this was done by directing the communication to individual students rather than to the class as whole. This teacher initiated interactions and received favourable responses from the students as evident in the almost equal number of frequencies of S-T recorded. Such interactions challenged the students' understanding of the course concept, provided them with different perspectives of the concept, thus promoting high level thinking and memory retention as well as better understanding of the course content.

Table 4. Numbers and types of interactions in Lesson $B$

\begin{tabular}{|l|l|l|l|l|l|l|l|l|l|l|l|}
\hline Types of interactions & \multicolumn{4}{|l|}{ Video displays } & \multicolumn{4}{|l|}{ Graphic displays } \\
\hline & T-C & T-S & S-T & S-C & S-S & T-C & T-S & S-T & S-C & S-S \\
\hline Social & 3 & 2 & 2 & & & & & & & \\
\hline Procedural & & & & & & & & & & \\
\hline Expository & 1 & & & & & 7 & 15 & 14 & & \\
\hline Explanatory & 7 & 5 & 6 & & & 7 & 8 & 6 & & \\
\hline Cognitive & & 15 & 16 & & & 1 & 23 & 26 & & \\
\hline
\end{tabular}

In Table 5, the distribution of the interactions in Lesson $C$ is depicted. Again as in Lesson $A$ and Lesson $\mathrm{B}$, a high degree of interactions took place in the expository, explanatory and cognitive dimensions wherein the teacher directed the questions to the students and the students responded to him as intended both in the video display mode as well as in the graphics display mode. It is therefore evident that the teacher was able not only to create a positive, stimulating and engaging learning environment but could use the interactions for instructional support that sought particular learning advantages and outcomes.

The results in Table 5 also revealed that the teacher had successfully utilised the opportunities afforded by the medium to support the preferred cognitive interactions. Supportive cognitive exchanges in the VCLE require a degree of skill and experience on the part of the teacher. It is a teaching skill that must be developed and acquired over time. It is evident that the results revealed the ability of the teacher to incorporate the interactive elements into his instructional programme in a planned and deliberate fashion, resulting in the observed high cognitive exchanges.

Table 5 also shows that the teacher used the video display and to a greater extent, the graphics display, to give instructions and directions and to present and deliver the lesson content in the form of two-way conversations with high dynamics of teachinglearning interactions. It therefore clear that the communicative capabilities of the technology had been utilised fully by the teacher to support two-way dialogues, interactions and reflection, successfully engaging the learners as co-participants in the learning process.

\section{Summary}

It is evident that the teachers in these three lessons appeared to recognise and appreciate the full potential of the VCLE; they were aware of the instructional strategies and practices that enable the VCLE to contribute significantly to lesson delivery. There was significant evidence of negotiation where students and teachers communicated on equal terms to pursue meaning or to construct personal ideas or models. 
Table 5. Numbers and types of interactions in Lesson $\mathbf{C}$

\begin{tabular}{|l|l|l|l|l|l|l|l|l|l|l|l|}
\hline Type of interactions & \multicolumn{4}{|l|}{ Video displays } & \multicolumn{4}{|l|}{ Graphic displays } \\
\hline & T-C & T-S & S-T & S-C & S-S & T-C & T-S & S-T & S-C & S-S \\
\hline Social & 1 & & & & & & & & & \\
\hline Procedural & & 2 & 3 & & & & & & & \\
\hline Expository & 1 & 1 & & & & & & & & \\
\hline Explanatory & 3 & 12 & 13 & & & 15 & 18 & 27 & & \\
\hline Cognitive & & 4 & 6 & & & 1 & 6 & 6 & & \\
\hline
\end{tabular}

The results revealed little evidence of the one-way story-telling or lecture-type mode of teaching where students listened and responded to the information supplied by the teacher. The teachers in all three lessons immersed themselves in a meaningful communication in the expository, explanatory and cognitive types of interactive domains where feedback plays an important part in the conversation with high degrees of teacher-initiated dialogues and student responses to teachers and peers.

Even though the learning environment was observed to be typically teacher-centered and strongly teacherdirected, a high degree of student participation and involvement was achieved. This environment was therefore considered suitable for the teaching of the courses being delivered and it is evident that the teachers have successfully used the instruction model that would enable students to seek high-order learning outcomes.

\section{Acknowledgement}

This research is supported by the Fundamental Research Grant Scheme (FRGS) account no: 203/PJJauh/670063

\section{References}

[1] Lensegrav, P. \& Pearce, K. (undated). The responsiveness of elementary students to the use of video conferencing.

http://www.bhsu.edu/education/edfaculty/kpearce/Re sponsiveness $\% 20$ of $\% 20$ Elementary $\% 20$ Students $\% 20$ to $\% 20$ Video $\% 20$ Conferencing.htm

[2] Roblyer, M.D. \& Ekhaml, L. (2000). How interactive are your distance courses? A rubric for assessing interaction in distance learning. Online Journal of Distance Learning Administration, 3(2). Online.

http://www.westga.edu/\%7Edistance/roblyer32.html
[3] Webb, N. (1991). Task verbal interaction and mathematics learning in small groups. Journal of Research in Mathematics Education, 22(5), 366-389.

[4] Bennett, N. \& Dunne, E. (1991). The nature and quality of talk in cooperative groups. Learning and Interaction, 1, 101-118.

[5] Oliver, R \& McLoughlin, C. (1997). Interactions in audiographics teaching and learning environments. The American Journal of Distance Education, 11(1), 34-54.

[6] Laurillard, D. (1993). Balancing the media. Journal of Educational Television, 19(2): 81-93.

[7] Moore, M. (1989). Three types of interaction. The American Journal of Distance Education, 3(2): 1-7.

[8] Fulford, C.P. \& Zhang, S. (1993). Perceptions of interactions: the critical predictor in distance education. The American Journal of Distance Education, 7(3), 8-21.

[9] Robson, J. (1996). The effectiveness of teleconferencing in fostering interaction in distance education. Distance Education, 17(2), 304-334.

[10] Oliver, R \& McLoughlin, C. (1997). Interactions in audiographics teaching and learning environments. The American Journal of Distance Education, 11(1), 34-54.

[11] Fahy, P.J. (2001). Indicator of support in online interaction. International Review of Open and Distance Learning, 4(1). Online.

http://www.irrodl.org/content/v4.1/fahy.html

[12] Foong, S.K., Rahman, Z.A., Atan, H., Mohamad, A.H., Hamdan, Z. \& Idrus, R.M. (2005). The distance education electronic portal: a study of the communicative dimensions in an asynchronous Forum Board. Proceedings of the Ed-Media 2005 World Conference on Educational Multimedia, Hypermedia \& Telecommunication, pp 955-959.

[13] Othman, S.A.S., Atan, H. \& Guan, C.K. (2005). The Open University Learning Management System: a study of interaction in the asynchronous Forum Board. International Journal of Instructional Technology \& Distance Learning, 2(11), 3-10. 